\title{
Oligodendrocytes in the mouse optic nerve originate in the preoptic area
}

Katsuhiko Ono $^{1)}$, Kengo Yoshii ${ }^{2)}$, Hiroyuki Tominaga ${ }^{1)}$, Hitoshi Gotoh ${ }^{1)}$, Tadashi Nomura ${ }^{1)}$, Hirohide

Takebayashi $^{3)}$, Kazuhiro Ikenaka ${ }^{4)}$

Departments of ${ }^{1)}$ Biology and ${ }^{2)}$ Mathematics, Kyoto Prefectural University of Medicine, Kyoto,

\author{
Japan \\ ${ }^{3)}$ Division of Neurobiology and Anatomy, Niigata University, Niigata, Japan \\ ${ }^{4)}$ Division of Neurobiology and Bioinformatics, National Institute for Physiological Sciences,
}

Okazaki, Japan

Running title: POA generates optic nerve OPC

Correspond to Katsuhiko Ono, $\mathrm{PhD}$,

Department of Biology, Kyoto Prefectural University of Medicine, Kyoto 606-0823, Japan

e-mail, katsono@koto.kpu-m.ac.jp, Tel/Fax +81-(0)75-703-4940 


\begin{abstract}
The present study aims to examine the origin of oligodendrocyte progenitor cells (OPCs) in the mouse optic nerve $(\mathrm{ON})$ by labeling OPCs in the fetal forebrain. The labeling of OPCs in the ON was performed by injection of a retrovirus vector carrying the lacZ gene into the lateral ventricle, or by inducible Cre/loxP of Olig2-positive cells. The retrovirus labeling revealed that ventricular zone-derived cells of the fetal forebrain relocated to the $\mathrm{ON}$ and differentiated into oligodendrocytes. In addition, lineage tracing of Olig2-positive cells and whole mount staining of PDGFR $\alpha$-positive cells demonstrated that OPCs appeared by E12.5 in the preoptic area, and spread caudally to enter the ON. Our results also suggest that OPCs generated during the early stage are depleted from the ON after maturation.
\end{abstract}

Key words

Olig2, PDGFR $\alpha$, CC1, LacZ, EGFP, Cre/loxP, retrovirus vector 


\section{Introduction}

Mechanisms underlying oligodendrocyte (OL) development have been uncovered by extensive studies after the isolation of O-2A (oligodendrocyte-type 2 astrocyte) progenitor cells from newborn rat optic nerves (ON) (Raff et al., 1984). One of the most remarkable findings is that PDGF is a strong mitogen for O-2A cells and that O-2A cells express PDGF receptor alpha (PDGFR $\alpha)$ (Richardson et al., 1988). O-2A cells differentiate into OLs when grafted into the forebrain of newborns (Espinosa de los Monteros et al., 1993), indicating that O-2A progenitors correspond to oligodendrocyte progenitor cells (OPCs) in vivo. PDGFR $\alpha$ is the first reliable lineage marker for OPC in vivo (Pringle et al., 1992). During the past quarter century, OPC

development has been extensively studied in the vertebrate central nervous system (Miller, 1996;

Miller, 2005; Naruse et al., 2016; Ono et al., 1995; Ono et al., 1997; Orentas and Miller, 1998;

Richardson et al., 2000). Although OPCs in the ON are considered to originate in the basal

forebrain (Garcion et al., 2001; Small et al., 1987), the precise origin of OPCs in the rodent ON has

not been examined experimentally.

The present study aims to elucidate the origin of OPCs in the ON in the developing mouse.

We used 2 strategies to label OPCs in the basal forebrain; the first is labeling mitotic cells in the fetal ventricular surface by an injection of high-titer retrovirus vector carrying the $l a c Z$ gene into the fetal lateral ventricle (Nanmoku et al., 2003), and the second is to label Olig2-positive progenitor cells 
with EGFP by ligand-inducible Cre/loxP (Masahira et al., 2006). The results suggest that OPCs in the $\mathrm{ON}$ arise in the preoptic area (POA) by E12.5, relocate caudally to enter the $\mathrm{ON}$, and differentiate to myelinating OLs, but not to GFAP-positive astrocytes. In addition, our results also suggest that OPCs generated in the early stage are depleted from the ON after maturation. 


\section{Results and Discussion}

\section{Cells derived from forebrain ventricular zone migrate to the $\mathrm{ON}$}

To examine whether forebrain ventricular zone (VZ)-derived cells at fetal stages migrate into the ON, we labeled VZ cells with high-titer retrovirus vector carrying the lacZ gene. When the retrovirus was injected into the fetal lateral ventricle at E12.5, E14.5, or E15.5, a considerable number of the VZ cells were labeled with LacZ 2 days after the injection. In later stages, a great number of LacZ+ cells were observed in the forebrain (Nanmoku et al., 2003). Among these cases, 2 ONs after the E14.5 injection and 2 after the E15.5 injection contained a great number of LacZ-positive cells; nearly 2,000 labeled cells were observed at P30 ( $n=2$ ONs) and approximately 800 cells at P180 ( $\mathrm{n}=2$ ONs) (Supplementary Table 1). No labeling was observed in the ON following the E12.5 injection. In the P30 ON, the labeled cells were densely distributed (Fig. 1A), and, therefore, individual cell morphology was not clear (Fig. 1B). In the P180 ON, nearly all, if not all, of the LacZ-positive cells had a cell body with several processes extended in parallel to the longitudinal axis of the ON (Fig. 1C), which is a typical myelinating OL shape. Astrocyte-like cells with a star shape were rarely detected in the ON (not shown). This result demonstrate that forebrain VZ-derived cells at these fetal stages relocate to the ON and differentiate into OLs.

\section{OPCs for ON may arise in the preoptic area}


We next examined the distribution of OPCs in the fetal basal forebrain close to the ON with

Olig2 and PDGFR $\alpha$ as markers. Olig2-positive cells were observed in the VZ of the POA and caudal hypothalamus, but not in the VZ in the level of the optic stalk at E12.5 (Supplementary Fig.

1). Whole mount staining of PDGFR $\alpha$ demonstrated that OPCs in the ventral diencephalon were initially localized in the anterior part of the POA at E13.5 (Fig. 2AC). Subsequently,

PDGFR $\alpha$-positive cells dispersed caudally to the rostral and caudal hypothalamus including the wall of the optic recess (Fig. 2BD). Coronal sections of E12.5-E14.5 basal forebrain and hypothalamus also showed a rostral-to-caudal gradient of distribution of PDGFR $\alpha$-positive OPCs and the POA contained the labeled cells most abundantly (Supplementary Fig. 2). The optic stalk is devoid of OPCs at these stages (supplementary Figs. 1GK and 2ILM).

We then performed short-term lineage tracing of Olig2-positive cells to examine when OPCs appeared in the ON. TM was injected into double-heterozygous animals at E11.5 or at E11.5+E12.5, and E17.5 ONs were observed after double-immunostaining for EGFP and PDGFR $\alpha$.

The results demonstrated that EGFP/PDGFR $\alpha$-double positive cells appeared in the ON treated with TM at E11.5+E12.5 (n=4 ONs, 2 mice; Supplementary Fig. 3AB; more than 70\% of EGFP-positive cells expressed PDGFR $\alpha$ ), while the ON at E11.5 did not contain EGFP-positive cells ( $\mathrm{n}=6,3$ mice; not shown), indicating that OPCs appeared in the ON in the forebrain by E12.5. 
We then performed short-term lineage tracing with a 1- or 2-day survival period after TM

treatment to observe the origin of OPCs retrospectively. In the E13.5 basal forebrain after E12.5

TM treatment, EGFP-positive cells in the POA expressed PDGFR $\alpha$ (Fig. 3A-D), while

EGFP-positive cells in the caudal hypothalamus were not positive for PDGFR $\alpha$ (Fig. 3EFG). In the

E15.5 or older forebrain, 3 or more days after TM treatment, EGFP/PDGFR $\alpha$ double-positive cells

were observed to enter the optic chiasm from the dorsally adjacent neuroepithelium ( $\mathrm{n}=6$ mice, Fig.

$3 \mathrm{GH})$.

\section{Olig2-positive cells in the E12.5 forebrain develop into myelinating OLs in the ON}

We next performed long-term lineage tracing of fetal Olig2-positive OPCs in the forebrain to

see whether they differentiated into myelinating OLs in the ON. Double-heterozygous animals

treated with TM at E12.5 were born and grew to P30 ( $\mathrm{n}=6$ mice) or P180 ( $\mathrm{n}=3$ mice). In both

stages (Fig. 4), EGFP-positive cells and processes formed clusters, which were localized

intermittently in the $\mathrm{ON}$ in both stages (Fig. 4A-C). The majority of EGFP-positive cells were

CC1-positive, and thus mature OLs (Fig. 4ACG). EGFP-positive processes were extended in

parallel to axon arrangement in longitudinal sections, and were positive for proteolipid protein (PLP),

a myelin protein (Fig. 4J). A small fraction of EGFP-positive cells were PDGFR $\alpha$-positive in the

P30 ON while no or few double-positive cells were detected at P180 (Fig. 4DEH). We estimated 
the total number of EGFP-positive cells in the ON. Approximately 800 cells were found in the P30

ON ( $n=6)$, although there was a large individual variation from 80 to 2,000, while nearly 400 cells

per ON were detected at P180 (Fig. 4F). In the P30 ON, 80\% of EGFP-positive cells were

CC1-positive mature OLs (Fig. 4A) and 11\% of them were PDGFR $\alpha$-positive OPCs (Fig. 4BGH).

In contrast, almost all EGFP-positive cells were CC1-positive mature OLs in the P180 ON, as

above-mentioned (Fig. 4GH).

We also stained the ON with anti-EGFP and anti-GFAP antibodies to examine whether fetal

Olig2-positive cells develop into astrocytes. No or few overlapping was noticed in the

double-stained sections from both P30 and P180 animals. Colocalization analysis in single optical

sections from the P30 ON demonstrated that EGFP-positive structures significantly overlapped more

often with PLP than with GFAP-positive structures (Fig. 4I-K). These results indicate that fetal

forebrain Olig2-positive cells relocate in the ON and develop into mature myelinating OLs, but not

astrocytes, and that early generated OPCs were depleted by the adult stage.

The present retrovirus injection study clearly demonstrated that OLs in the ON are derived

from forebrain VZ cells in the fetal stage. In addition, whole-mount immunostaining of PDGFR $\alpha$

revealed that OPCs in the hypothalamic area were initially restricted to the POA, and therefore, the

POA is the site of OPC origin in the ON. We previously demonstrated in chick embryos that OPCs

arise from the floor of the third ventricle adjacent to the optic chiasm (Ono et al., 1997). In the 
present study, EGFP/PDGFR $\alpha$ double-positive cells were observed in the chiasmal region at E15.5.

However, no Olig2-positive cells were observed in the future chiasmal region at E12.5

(Supplementary Fig. 1) when TM treatment was performed. Short-term lineage tracing

demonstrated that double-positive cells were most abundant in the POA, whereas none of the

EGFP-positive cells were PDGFR $\alpha$-positive in the caudal hypothalamus. Olig2-positive cells in

the caudal hypothalamus co-express neurogenin-2 (Ono et al., 2009), and therefore these cells

probably differentiate into neurons, but not into OPCs. These results strongly indicate that

chiasmal double-positive cells are derived from the POA. Together, these results suggest that OPCs

in the ON arise in the anterior part of the POA (Supplementary Fig. 4). In the late fetal stages,

Olig2-positive cells are distributed not only in the POA, but also the rostral and caudal hypothalamus

(Ono et al., 2008). Such Olig2 cells could also generate OPCs in the hypothalamus and the ON,

and will need to be uncovered by future analysis.

O-2A progenitor cells in vitro differentiate into either type 2 astrocytes or into OLs, whereas

they differentiate into OLs when they are grafted to the forebrain of newborns (Espinosa de los

Monteros et al., 1993; Raff et al., 1984). In the present study, most, if not all, VZ-derived cells

labeled with LacZ differentiated to OLs in the ON (Fig. 1C), while astrocyte-like cells were rarely

detected in the ON. In addition, Olig2-positive cells which migrated to the ON from the forebrain

were shown to develop only into OLs. Although colocalization analysis showed that $10 \%$ of 
EGFP-positive structures overlapped with GFAP-positive structures, we did not observe overlapping distribution of EGFP with GFAP in the ON. Only PLP- or CC1-positive structures were clearly colocalized with EGFP-positive structures. Therefore, the present result indicates that OPCs in vivo do not differentiate into astrocytes in the ON. Olig2-positive progenitor cells have been reported to differentiate into astrocytes as well as OLs in other regions of the CNS (Ono et al., 2008;

Tatsumi et al., 2008), indicating that there might be inhibitory factors in the ON for OPCs to develop to astrocytes, which are specifically localized in the ON.

In conclusion, the present study demonstrated that OPC in the ON arise in the POA of the developing mouse brain by E12.5, probably under the influence of local signals, such as sonic hedgehog (Orentas et al., 1999), expressed in the POA (Ono et al., 2008). They gradually disperse caudally to enter the $\mathrm{ON}$ from the chiasmal region. There may be species difference between the mouse and the chick with respect to the origin of early OPCs in the ON (mouse, present study; chick, Ono et al., 1997). A phylogenic comparative study would elucidate the significance of species differences. 


\section{Materials and methods}

\section{Animals and tissue preparation}

The animals used in this study were Olig2 ${ }^{\text {KICreER }}$ (Takebayashi et al., 2002), ROSA26-GAP43-EGFP

(Nakahira et al., 2006), and wild-type ICR mice (Slc, Shizuoka, Japan). The day when the vaginal

plug was detected was regarded as E0.5. Genotyping was performed as previously described

(Takebayashi et al., 2002; Tatsumi et al., 2008). All animal experiment procedures were approved

by the Animal Research Committee of Kyoto Prefectural University of Medicine and of National

Institute for Physiological Sciences.

To label Olig2 lineage cells, Olig2 ${ }^{\mathrm{KICreER}}$;ROSA26-GAP43-EGFP double heterozygous mice

were mated with wild-type mice, and tamoxifen (TM; $3 \mathrm{mg} / \mathrm{animal})$ was intraperitoneally injected

into pregnant mothers with fetuses at E11.5 or E11.5 and E12.5 (E11.5+E12.5), E12.5, E14.5, or

E15.5, as previously described (Masahira et al., 2006). Pregnant mice were deeply anesthetized

with pentobarbital (100 mg/kg body weight), and fetal mice were removed from the uterus. Fetal

mice brains at E15.5 or younger were fixed by immersion in $4 \%$ paraformaldehyde (PFA) in

phosphate-buffered saline (PBS) overnight. Mouse brains at E17.5 or after birth were fixed by

perfusion with $4 \%$ PFA through the heart, and the ON was isolated and immersed in $20 \%$ sucrose in

PBS. The ON was cut transversely or longitudinally with a cryostat at $20 \mu \mathrm{m}$ in thickness, and

sections were thaw-mounted onto MAS-coated glass slides (Matsunami Glass Co., Tokyo, Japan). 
Nomenclature of fetal brain structures is according to that used by Bulfone et al. (Bulfone et al.,

1993) and by Nieuwenhuys et al. (Nieuwenhuys et al., 2008).

\section{Production and injection of high-titer retrovirus vector}

Preparation of a retrovirus vector carrying the lac $Z$ gene and injection of the vector into the fetal lateral ventricle were performed as previously reported (Nanmoku et al., 2003). We used the

$\mathrm{ON}$ of the same samples as the previous report. The ON was cut with a vibratome at $100 \mu \mathrm{m}$ in thickness and stained with X-Gal as previously reported (Nanmoku et al., 2003).

\section{Immunohistochemistry and in situ hybridization}

Immunohistochemistry was carried out as previously described (Ono et al., 2014). Primary antibodies used are listed in Supplementary table 1. In situ hybridization of PDGFR $\alpha$ was

performed as previously described (Ivanova et al., 2003). Stained sections were observed under an epifluorescent or bright field microscope (BX-51; Olympus, Tokyo, Japan), or with a confocal laser scanning microscope (CLSM; FV-1000; Olympus).

Whole-mount immunohistochemistry of PDGFR $\alpha$ was performed in E13.5 E15.5 brains that were cut along the midline. They were treated with $0.1 \% \mathrm{H}_{2} \mathrm{O}_{2}$ for 4 hours, with $2 \%$ BSA and $5 \%$ dimethylsulfoxyde for 5 hours, and subsequently incubated with primary antibody (1:1000) 
overnight. They were washed 3 times for 4 hours, and then incubated with biotinylated anti-goat

antibody (1:1000) for 5 hours. After washing, they were processed with an ABC elite kit, color

was developed by incubation with tris- $\mathrm{HCl}(50 \mathrm{mM}, \mathrm{pH} 7.4)$ containing diaminobenzidine and $\mathrm{H}_{2} \mathrm{O}_{2}$,

and they were observed under a dissection microscope (SZX7, Olympus). Olig2-KO brains were

used as a negative control.

\section{Image analysis}

Colocalization analysis was performed with Fiji/ImageJ software (NIH). Dual color images

of EGFP and GFAP, or of EGFP and PLP, were captured with a FV1000 CLSM. Manders split

coefficients (Manders et al., 1993) above the threshold (tM) were calculated, which indicated,

proportional to the amount of fluorescence, the colocalizing pixels in each color channel. Five

regions from 1 image were averaged, and at least 3 images were analyzed and compared between

GFAP and PLP. 


\section{Acknowledgement}

We would like to express our sincere appreciation to Ms. Masako Kawano for technical help, and to

Dr. Martin Goulding for providing a reporter mouse. This work was supported by a Grant-in-Aid

for Scientific research provided by MEXT, and also by a collaboration Grant provided by NIPS. 


\section{Figure legends}

Figure 1 LacZ-positive cells in the adult ON following retroviral injection into the fetal

\section{lateral ventricle}

(A) A low magnification picture of the P30 ON following E15.5 viral injection. (B) A high

magnification picture of the P30 ON. (C) LacZ-positive cells in the P180 ON following E15.5 viral

injection. The labeled cells show profiles of oligodendrocytes.

Figure 2 Initial appearance and dispersal of OPCs in the hypothalamus.

Whole-mount immunohistochemistry of PDGFR $\alpha$. Medial view of the brains cut along the midline.

Boxed areas in A and B are magnified in C and D, respectively. Arrows indicate the optic recess.

(A) E13.5. PDGFR $\alpha$-positive cells are observed in the rostral part of the preoptic area (arrowhead).

(B) E15.5. PDGFR $\alpha$-positive cells are widely distributed in the preoptic area (arrowhead), and

scattered caudally beyond the optic recess (arrow). Asterisks in C and D indicate interventricular

foramen. Cx, cerebral cortex. DTh, dorsal thalamus, Hyth, hypothalamus. $\quad$ Bars $=500 \mu \mathrm{m}$.

Figure 3 Olig2 lineage PDGFRa-positive cells in the basal forebrain and the $\mathrm{ON}$ at fetal

stages.

(A-F) EGFP-positive cells in the E13.4 basal forebrain following E12.5 TM injection. Nearly all 
EGFP-positive cells in the preoptic area (POA) and rostral hypothalamus (Hyth) are

PDGFR $\alpha$-positive (A-D; arrowheads), while EGFP-positive cells in the caudal hypothalamus are not

(arrows). (G) The percentage of EGFP/PDGFR $\alpha$ double-positive cells in the EGFP-positive cell

population in the hypothalamus. Sections were grouped as the anterior (A), middle (C), and

most-caudal (E) levels ( $\mathrm{n}=3$ mice). (H, I) EGFP/PDGFR $\alpha$ double-positive cells (arrowhead) are

observed to enter the optic chiasm from the overlying neuroepithelium at E15.5. Boxed areas in the

left columns are magnified in the right columns. Bars in $\mathrm{B}, \mathrm{D}, \mathrm{F}$, and $\mathrm{I}=50 \mu \mathrm{m}$; in $\mathrm{E}, \mathrm{H}=500 \mu \mathrm{m}$

Figure 4 Appearance of Olig2-lineage cells in the adult ON following E12.5 TM injection.

(A, B) Longitudinal sections of the P30 ON, double-stained with anti-EGFP and anti-CC1 (A; OLs)

or anti-PDGFR $\alpha(\mathrm{B}$; OPCs) antibodies. Boxed area in C is magnified in the inset. (E) EGFP/CC1

double-positive cells in the coronal section of the P180 ON. Arrowheads indicate double-positive

cells. (F) Appearance of EGFP/PDGFR $\alpha$ double-positive OPCs in the P30 ON. (G) No or few

EGFP/PDGFR $\alpha$ double-positive OPCs in the P180 ON. (H) Estimation of the total EGFP-positive

cells in single ONs at P30 (n=6 ONs) and P180 (n=6). (I) Percentage of EGFP/CC1

double-positive cells among the EGFP-positive cell population. (n=6 in P30 and P180). (J)

Percentage of EGFP/PDGFR $\alpha$ double-positive cells among the EGFP-positive cell population. $(\mathrm{n}=4$

in P30 and $n=6$ in P180). (K-M) Colocaliztion analysis of EGFP-positive structures with glial 
bioRxiv preprint doi: https://doi.org/10.1101/078774; this version posted October 1,2016 . The copyright holder for this preprint (which was not certified by peer review) is the author/funder. All rights reserved. No reuse allowed without permission.

structures in the P30 ON. EGFP-positive structures colocalized with PLP (L and M) significantly

more than with GFAP $(K) . \quad$ Bar in $D=200 \mu \mathrm{m}$; in $A, C, E, J=50 \mu \mathrm{m}$; in $B=25 \mu \mathrm{m}$. 


\section{References}

Bulfone, A., Puelles, L., Porteus, M. H., Frohman, M. A., Martin, G. R. and Rubenstein, J. L. (1993). Spatially restricted expression of Dlx-1, Dlx-2 (Tes-1), Gbx-2, and Wnt-3 in the embryonic day 12.5 mouse forebrain defines potential transverse and longitudinal segmental boundaries. The Journal of neuroscience : the officialjournal of the Society for Neuroscience 13, 3155-3172.

Espinosa de los Monteros, A., Zhang, M. and De Vellis, J. (1993). O2A progenitor cells transplanted into the neonatal rat brain develop into oligodendrocytes but not astrocytes. Proceedings of the National Academy of Sciences of the United States of America 90, 50-54.

Garcion, E., Faissner, A. and ffrench-Constant, C. (2001). Knockout mice reveal a contribution of the extracellular matrix molecule tenascin- $\mathrm{C}$ to neural precursor proliferation and migration. Development 128, 2485-2496.

Ivanova, A., Nakahira, E., Kagawa, T., Oba, A., Wada, T., Takebayashi, H., Spassky, N., Levine, J., Zalc, B. and Ikenaka, K. (2003). Evidence for a second wave of oligodendrogenesis in the postnatal cerebral cortex of the mouse. Journal of neuroscience research 73, 581-592.

Manders, E. M. M., Verbeek, F. J. and Aten, J. A. (1993). Measurement of co-localization of objects in dual-colour confocal images. J Microscop 169, 375-382.

Masahira, N., Takebayashi, H., Ono, K., Watanabe, K., Ding, L., Furusho, M., Ogawa, Y., Nabeshima, Y., Alvarez-Buylla, A., Shimizu, K., et al. (2006). Olig2-positive progenitors in the embryonic spinal cord give rise not only to motoneurons and oligodendrocytes, but also to a subset of astrocytes and ependymal cells. Developmental biology 293, 358-369.

Miller, R. H. (1996). Oligodendrocyte origins. Trends in neurosciences 19, 92-96.

--- (2005). Dorsally derived oligodendrocytes come of age. Neuron 45, 1-3.

Nakahira, E., Kagawa, T., Shimizu, T., Goulding, M. D. and Ikenaka, K. (2006). Direct evidence that ventral forebrain cells migrate to the cortex and contribute to the generation of cortical myelinating oligodendrocytes. Developmental biology 291, $123-131$.

Nanmoku, K., Kawano, M., Iwasaki, Y. and Ikenaka, K. (2003). Highly efficient gene transduction into the brain using high-titer retroviral vectors. Developmental neuroscience 25, 152-161.

Naruse, M., Ishino, Y., Kumar, A., Ono, K., Takebayashi, H., Yamaguchi, M., Ishizaki, Y., 
Ikenaka, K. and Hitoshi, S. (2016). The Dorsoventral Boundary of the Germinal Zone is a Specialized Niche for the Generation of Cortical Oligodendrocytes during a Restricted Temporal Window. Cerebral cortex 26, 2800-2810.

Nieuwenhuys, R., Voogd, J. and van Huijzen, C. (2008). The human central nervous system. Berlin: Springer-Verlag.

Ono, K., Bansal, R., Payne, J., Rutishauser, U. and Miller, R. H. (1995). Early development and dispersal of oligodendrocyte precursors in the embryonic chick spinal cord. Development 121, 1743-1754.

Ono, K., Clavairoly, A., Nomura, T., Gotoh, H., Uno, A., Armant, O., Takebayashi, H., Zhang, Q., Shimamura, K., Itohara, S., et al. (2014). Development of the prethalamus is crucial for thalamocortical projection formation and is regulated by Olig2. Development 141, 2075-2084.

Ono, K., Takebayashi, H., Ikeda, K., Furusho, M., Nishizawa, T., Watanabe, K. and Ikenaka, K. (2008). Regional- and temporal-dependent changes in the differentiation of Olig2 progenitors in the forebrain, and the impact on astrocyte development in the dorsal pallium. Developmental biology 320, 456-468.

Ono, K., Takebayashi, H. and Ikenaka, K. (2009). Olig2 transcription factor in the developing and injured forebrain; cell lineage and glial development. Molecules and cells 27, 397-401.

Ono, K., Yasui, Y., Rutishauser, U. and Miller, R. H. (1997). Focal ventricular origin and migration of oligodendrocyte precursors into the chick optic nerve. Neuron 19, 283-292.

Orentas, D. M., Hayes, J. E., Dyer, K. L. and Miller, R. H. (1999). Sonic hedgehog signaling is required during the appearance of spinal cord oligodendrocyte precursors. Development 126, 2419-2429.

Orentas, D. M. and Miller, R. H. (1998). Regulation of oligodendrocyte development. Molecular neurobiology 18, 247-259.

Pringle, N. P., Mudhar, H. S., Collarini, E. J. and Richardson, W. D. (1992). PDGF receptors in the rat CNS: during late neurogenesis, PDGF alpha-receptor expression appears to be restricted to glial cells of the oligodendrocyte lineage. Development 115, $535-551$.

Raff, M. C., Williams, B. P. and Miller, R. H. (1984). The in vitro differentiation of a bipotential glial progenitor cell. The EMBO journal 3, 1857-1864.

Richardson, W. D., Pringle, N., Mosley, M. J., Westermark, B. and Dubois-Dalcq, M. (1988). A role for platelet-derived growth factor in normal gliogenesis in the central nervous system. Cell 53, 309-319. 
Richardson, W. D., Smith, H. K., Sun, T., Pringle, N. P., Hall, A. and Woodruff, R. (2000). Oligodendrocyte lineage and the motor neuron connection. Glia 29, 136-142.

Small, R. K., Riddle, P. and Noble, M. (1987). Evidence for migration of oligodendrocyte--type-2 astrocyte progenitor cells into the developing rat optic nerve. Nature 328, 155-157.

Takebayashi, H., Nabeshima, Y., Yoshida, S., Chisaka, O., Ikenaka, K. and Nabeshima, Y. (2002). The basic helix-loop-helix factor olig2 is essential for the development of motoneuron and oligodendrocyte lineages. Current biology : CB 12, 1157-1163.

Tatsumi, K., Takebayashi, H., Manabe, T., Tanaka, K. F., Makinodan, M., Yamauchi, T., Makinodan, E., Matsuyoshi, H., Okuda, H., Ikenaka, K., et al. (2008). Genetic fate mapping of Olig2 progenitors in the injured adult cerebral cortex reveals preferential differentiation into astrocytes. Journal of neuroscience research 86 , 3494-3502. 
A optic nerve

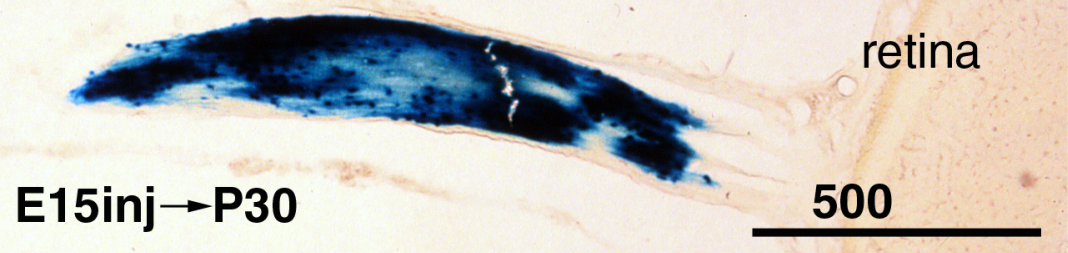

B

\section{E15inj $\rightarrow$ P30}

C

\section{$\mathrm{E} 15 \mathrm{inj} \rightarrow \mathrm{P} 180$}

50

Ono et al.,

Fig. 1 


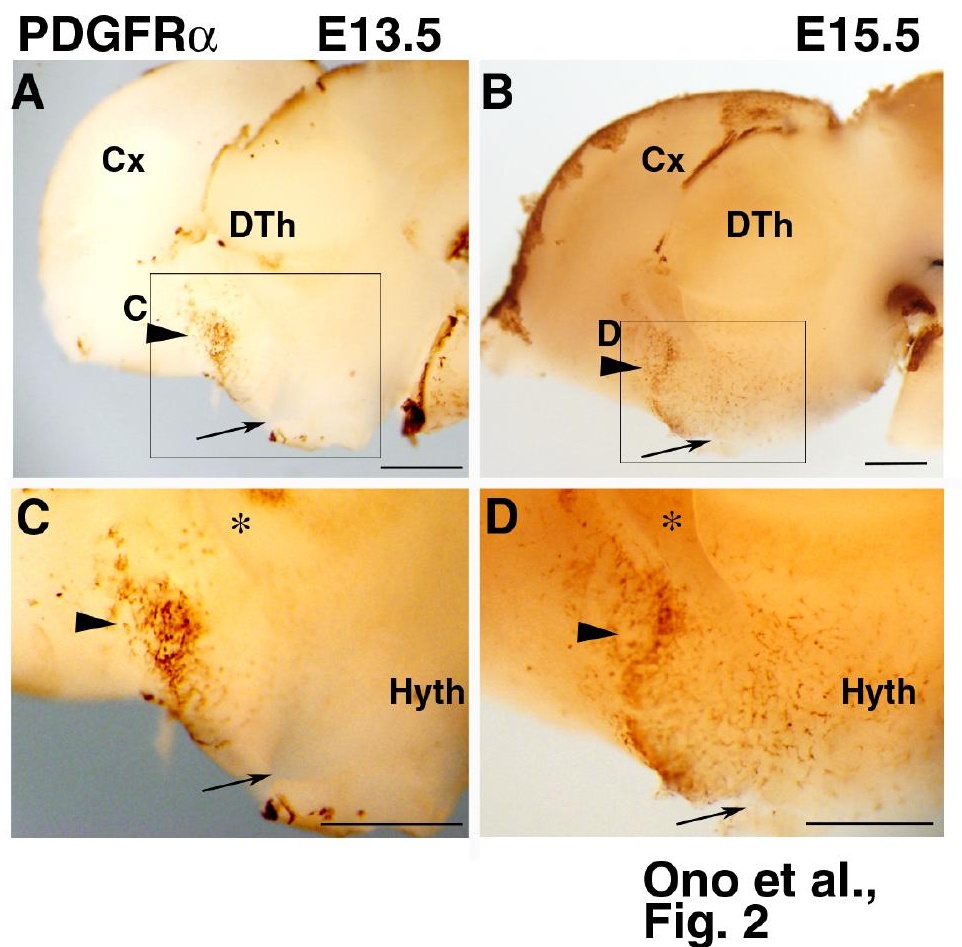




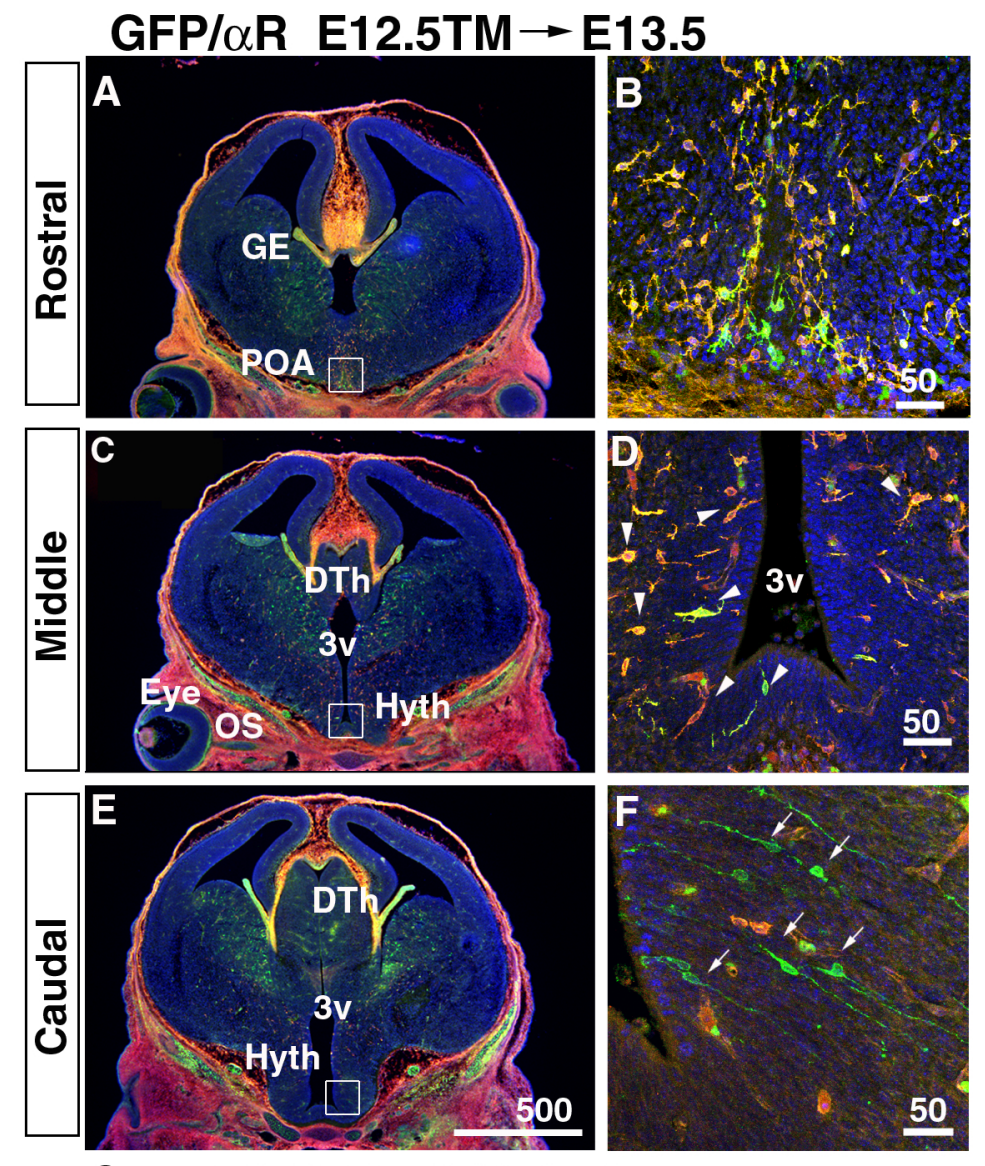

G $\%$ of (GFP/ $\alpha R)$ cells/GFP cells in the hypothalamus

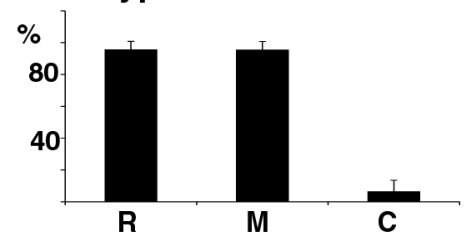

$\mathrm{GFP} / \alpha R \quad \mathrm{E} 12.5 \mathrm{TM} \rightarrow \mathrm{E} 15.5$

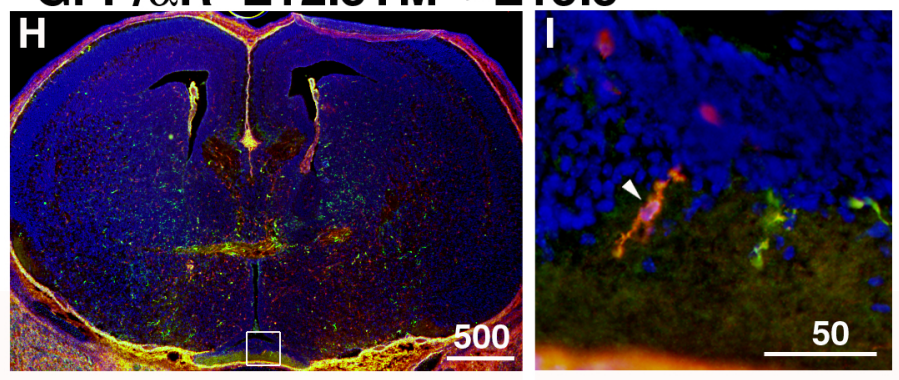

Ono et al., Fig. 3 


\section{A GFP/CC1}

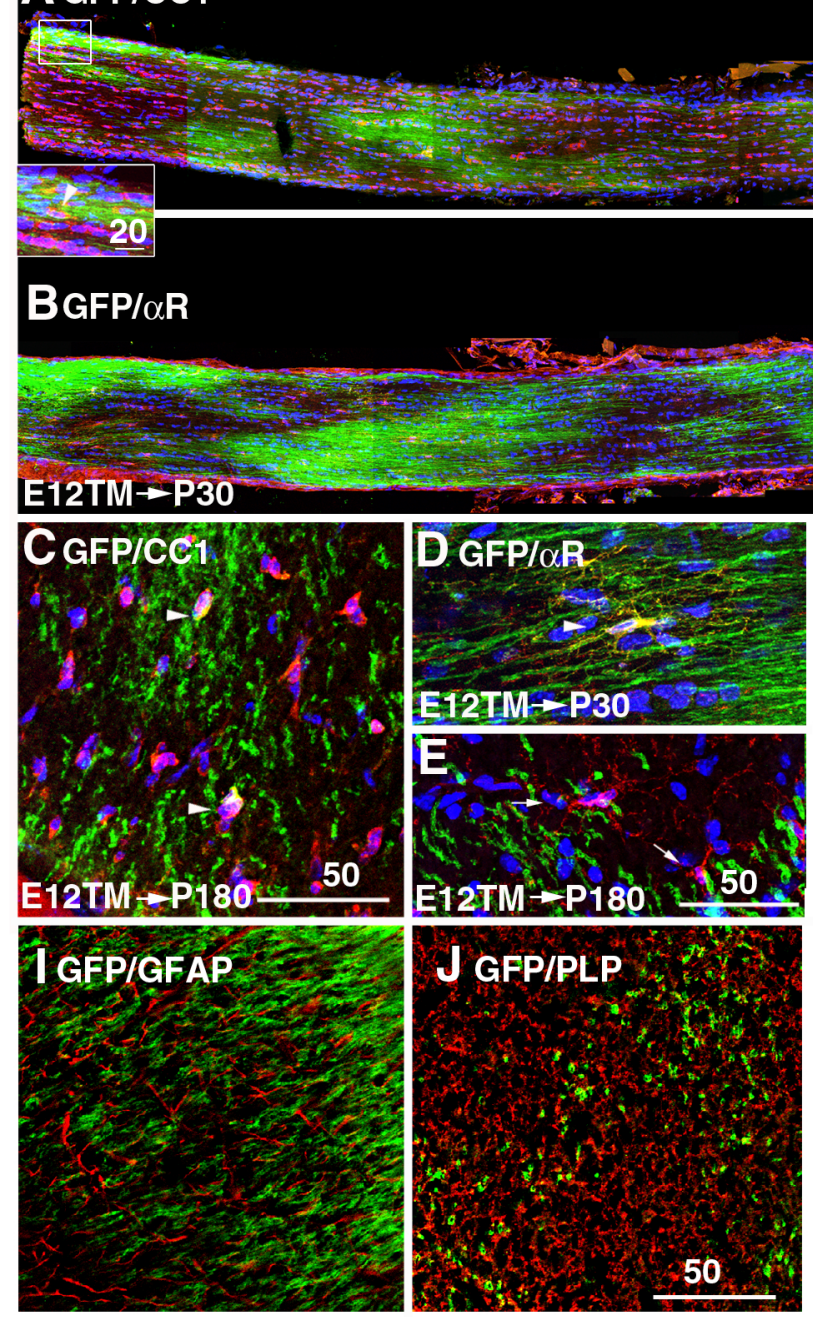

\section{sterasessin:}

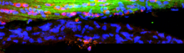

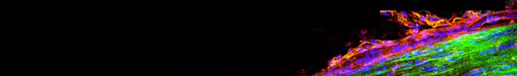

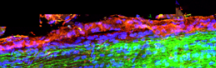

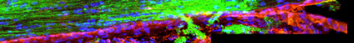

$\mathbf{F}$

total GFP+ cells

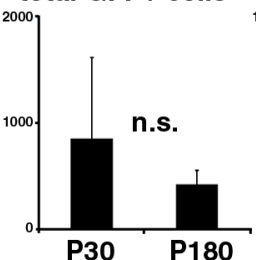

G

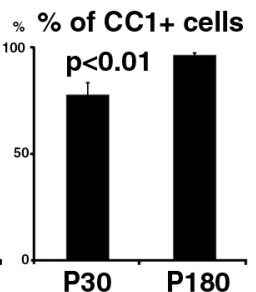

K

Colocalization of GFP with glial structures

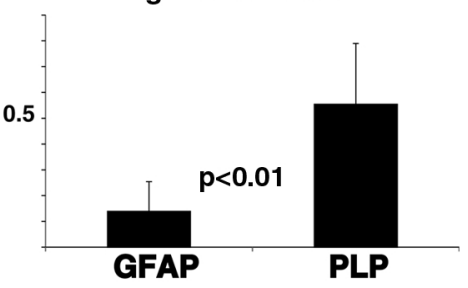

GFAP

\section{H}

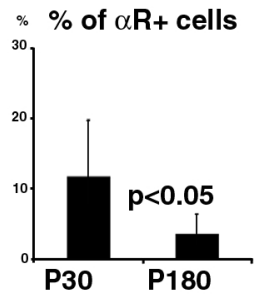

Ono et al., Fig. 4 